\title{
Hydrogen Production by water Electrolysis with an Ultrathin Anion-exchange membrane (AEM)
}

\author{
Immanuel Vincent, Andries Kruger and Dmitri Bessarabov ${ }^{*}$ \\ DST HySA Infrastructure Centre of Competence, Faculty of Engineering, \\ North-West University, Potchefstroom, 2520, South Africa \\ *E-mail: Dmitri.bessarabov@nwu.ac.za
}

doi: $10.20964 / 2018.12 .84$

Received: 30 August 2018 / Accepted: 5 October 2018 / Published: 5 November 2018

\begin{abstract}
A new ultrathin anion exchange membrane (AEM) is proposed for low cost AEM electrolysis. The advantages that thin membranes offer include reduced mass transport resistance and ohmic resistance. A membrane electrode assembly (MEA) with a thinner membrane will have improved hydroxide ion transfer due to the shorter ion transfer pathway. We fabricated a MEA with a commercially available ultrathin A-901 membrane ( $9 \mu \mathrm{m}$ thick) and non-noble metal catalysts. We determined the efficiency and stability of this ultrathin membrane using electrochemical impedance spectroscopy. The best performance recorded was $400 \mathrm{~mA} \mathrm{~cm}^{-2}$ at $1.94 \mathrm{~V}$ at $50{ }^{\circ} \mathrm{C}$. Over a period of $200 \mathrm{~h}$, the voltage increase was only $200 \mu \mathrm{V} \mathrm{h}^{-1}$, which is $<60 \%$ that of the more commonly used A-201 membrane. The ultrathin A-901 membrane exhibited slightly higher performance compared to the A-201 for a given catalyst, catalyst loading, and electrolyte concentration. Acta $3030^{\circledR}\left(\mathrm{CuCoO}_{\mathrm{x}}\right)$ and Acta $4030^{\circledR}$ $\left(\mathrm{Ni} /\left(\mathrm{CeO}_{2}-\mathrm{La}_{2} \mathrm{O}_{3}\right) / \mathrm{C}\right)$ were employed as the oxygen evolution reaction and hydrogen evolution reaction catalysts, respectively.
\end{abstract}

Keywords: A-901 AEM membranes, A-201 AEM membranes, Membrane electrode assembly, Oxygen evolution reaction, Hydrogen evolution reaction, Electrochemical impedance spectroscopy.

\section{$\underline{\text { FULL TEXT }}$}

(C) 2018 The Authors. Published by ESG (www.electrochemsci.org). This article is an open access article distributed under the terms and conditions of the Creative Commons Attribution license (http://creativecommons.org/licenses/by/4.0/). 